The smallest bubbles, from the bare spaces, leave a complote skin of carbon, ruptured in one place only. The central bubble gives rise to a very fino deposit of carbon, only a fifth to a tenth of that from an intermediate zono bubble.

The density of the bubbles is thus determined by the carbon load which they have carried away from the film. I have boen unable to find any signs of the formation of clear spaces by the concentration of the removed carbon round their edges. Indeed, the observation just quoted scems decisive.

If the second effect (formation of gas bubbles) is due to the adsorption of gas by carbon during the formation of the film, one would expect that a film formed in a stream of ammonia gas would give a much more marked effect on impact, since charcoal is stated to adsorb ten times as much ammonia by volume as it does air 4 .

On forming a film in a stream of ammonia, however, no difference could bo observed in the figure formed from one formed in a similar way on a film made in air. It seems probable, therefore, that the gas is not adsorbed by the carbon, but is entrapped between successive layers of the film. This would account for the fact that no evolution of gas occurs from the surface of the film, even the central bubble (the most suporficial to arise) having to raise a fine cont of carbon before it is liberated.

It is possible that the circle of clear dots formed round the central zono is due to a shock transmitted to the deepest layers of the film during the formation of the central zone.

Clare College, Cambridge. D. MaLCOHM CARDING. July 19

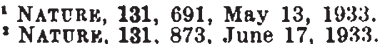

NATURE, 131, 873, June 17, 1933.

- Partington, "Inorganic Chemistry", p. 657.

\section{Nuclear Spin and Magnetic Moment of Tin}

Previous investigators have failed to record any fine structures in the spectra of $\operatorname{tin}^{1}$. By the use of a Fabry-Perot interferometer I have examined the spectrum of Sn II emitted by a hollow cathode discharge, and obtained structures in several lines. Aston reports 11 tin isotopes within the rango 112 124, and of those, 76 per cent are even whilst the percentage abundances of the odd isotopes are $115=0 \cdot 4,117=9 \cdot 8,119=11,121=2 \cdot 9$.

The line $6 s .{ }^{2} S_{12}-6 p .{ }^{2} P_{3}{ }_{2}$ has the following structure (intensities in brackets).

$$
+53(3) 0(15)-152(1) \mathrm{cm} .^{-1} \times 10^{-3} \text {. }
$$

Other lines show $6 p^{2} P_{32}$ to have a negligible structure so that only $6 s .{ }^{2} S_{1 / 2}$ is split up. The intensities show that the strong component, which is at the centre of gravity of the structure, is due to the even isotopes, and as the intensity ratio of tho outer lines is 3 : I the nuclear spin is $\frac{1}{2}$. This must be true at least for 117 and 119 , since tho satellites are about 21 per cent of the total intensity. The value for the spin is chocked by the fact that the intervals from the centre component are in tho ratio $1: 3$ within experimental limits.

Only the stronger of the two expected satellites has been found in $6 s .{ }^{2} S_{1 / 2}-6 p .{ }^{2} P_{1_{2}}$ owing to falling off in plate sensitivity.

Tho $5 d .{ }^{2} D_{6}{ }_{2}$ term shows broadening in the even isotope term and a doublet structure greater than that of $68 .{ }^{2} S_{12}$ whilst $5 d .{ }^{2} D_{32}$ also shows a definite, although unresolved, broadening, due doubtless to even isotope displacoment. These structures aro almost certainly due to perturbations by the noighbouring $s \cdot p^{2} .^{2} D_{3 / 2} 3 / 2$ terms ${ }^{2}$.

The structures in both $6 s .{ }^{2} S_{1.2}$ and $5 d .{ }^{2} D_{5 / 2}$ are inverted, the higher $F$ term lying deepest, hence the nuclear magnetic moment is negative as in the case of cadmium. Tho $g(I)$ factor when calculated by Goudsmit's formula ${ }^{3}$ is $-1 \cdot 81$.

Full details will be published elsewhere.

Astro-Physics Department, S. Tolansky.

$$
\begin{aligned}
& \text { Astro-Physics Department, } \\
& \text { Imperial College of Science, } \\
& \text { South Kersington, } \\
& \text { London. } \\
& \text { Aug. 1. } \\
& \text { 'Murakawa, Z. Phys., 72, 793; 19:31. } \\
& \text { 2 Lang, Phys. Rev., 35, 445; 19:30. } \\
& \text { J Goudsmit, Phys. Rev., 43, 637; 1933. }
\end{aligned}
$$

\section{Vanadium Oxide Bands}

Mecke and Guillery ${ }^{2}$ identified only four band heads given in Kayser's "Handbuch der Spectroscopic" $(6,786,1912)$ as due to the oxide of vanadium and assigned them their vibration quantum numbers. These aro the $(1,0),(0,0),(0,1)$ and $(0,2)$ band heads. Prof. Ferguson" has recently photographed the bands and measured thirty-one heads from low dispersion spectrograms between $\lambda 4800$ and $\lambda 8700$. The bands have now been photographed under high dispersion and more accurate data have been secured. The measurements have also been extended in the shorter wave-length region as far as $\lambda 4500$. The band. heads are double with a separation of about $2 \cdot 8 \mathrm{v}$ between them. The equation of band head wave numbers remains, however, practically the samo as that given by Prof. Ferguson.

A preliminary analysis of the rotational structure of $(0,1),(0,0)$ and $(1,0)$ bands shows that the band system is due to a ${ }^{2} \Sigma \rightarrow 2 \sum$ transition. The following rotational constants have been approximately evaluated.

$$
\begin{array}{ll}
B_{e}^{\prime \prime}=0.526 \mathrm{~cm} .^{-1} & B_{e}^{\prime}=0.489 \mathrm{~cm}^{-1} \\
r_{e}^{\prime \prime}=1.62 \mathrm{~A} . & r_{e}^{\prime}=1.68 \mathrm{~A} .
\end{array}
$$

A detailed account of the analysis and more precise value of tho constants will be published elsewhere.

\section{Chandraserhar Ghosh.}

Applied Physics Iaboratory

University College of Science and Technology, Calcutta.

June 27.

'Phys. Z., 28, 514; 1927.

Bureau Standards J. Res., 8, 382; 1932.

\section{Karagwe-Ankolean Rocks as a Repository of Gold}

Witr reference to the penultimate paragraph of Dr. Parkinson's article on "Central African Volcanoes" in NATURE of Juno 10, may I bo permitted to state, in the interests of accuracy, that the Karagwe-Ankolean rocks of Kigezi, Uganda, were known to be repositorios of gold, in tho sense that they aro also repositories of tin, before tho auriferous alluvials and lodes of Kakamega were discovered.

Geological Survey Office, E. J. WAYLAND. P.O. Box 9,

Entebbe, Uganda. July 17. 